\title{
A COMPARISON OF NON-RADIOACTIVE METHODS FOR ASSESSING VIABILITY IN EX VIVO CULTURED CANCELLOUS BONE: TECHNICAL NOTE
}

\author{
MJ Stoddart, PI Furlong, A Simpson, CM Davies, RG Richards* \\ AO Research Institute, AO Foundation, Davos, Switzerland
}

\begin{abstract}
Biocompatibility studies are carried out either in two dimensional monolayer culture or in animal studies. Bone organ cultures are therefore required in order to reduce the number of animal studies performed, while at the same time ensuring a more natural environment than that provided by monolayer culture of isolated cells. Due to the three dimensional nature of bone explants, assays that determine the distribution of viable cells are required, however dense mineralised bone is not easily penetrated by soluble factors. We sought to compare a number of non-radioactive viability methods in order to assess their suitability for use with cancellous bone. Fluorescent live/dead staining, MTT activity and lactate dehydrogenase detection were all investigated on either whole bone explants $(9.5 \mathrm{~mm}$ in diameter, $5 \mathrm{~mm}$ high) or on sections of explants. All these assays are routinely used in 2 dimensional cell culture systems, yet each required modifications to be suitable for use with cancellous bone. Factors such as penetration of reagent, incubation time, assay temperature and ease of determining viable cells were all compared. It was demonstrated that penetration of the reagents into whole cores was a major problem which easily led to artefacts that could be overcome by preparing $250 \mu \mathrm{m}$ unfixed sections. Fluorescent live/dead staining had extra complications caused by the autofluorescence of the bone generating a high signal to noise ratio, making assessment of osteocyte viability impossible. MTT staining was difficult to interpret due to the punctate nature of the stain. We found that lactate dehydrogenase staining of $250 \mu \mathrm{m}$ thick unfixed sections led to excellent viability determination of osteocytes within the mineralised matrix. It also maintained marrow structure. Decreasing the viscosity of the LDH assay solution used in published methods led to a greatly improved penetration into the calcified matrix. Quantification of thick sections is aided by using the autofluorescence of the bone to highlight the darkly stained osteocytes against the fluorescing bone.
\end{abstract}

Keywords: Bone, three dimensional, viability, methods

\author{
*Address for correspondence: \\ R.G. Richards \\ AO Research Institute \\ AO Foundation \\ Clavadelerstrasse 8 \\ CH7270 Davos Platz \\ Switzerland
}

Tel: +41 (0)814142397

E-mail:geoff.richards@aofoundation.org

\section{Introduction}

Long term culture of cancellous bone explants provides an opportunity to investigate the role of external factors on the turnover and development of bone, while maintaining complex inter-cellular signalling. Organ culture of cancellous bone opens up new opportunities for biocompatibility studies, providing an intermediate between monolayer culture and animal studies. In vivo the vascular system ensures that no bone cell is further than $\sim 100 \mu \mathrm{m}$ from a blood vessel, and hence the cells are well nourished. On removal from the body, the connections to the vasculature are cut and the cells within the explant rely entirely on diffusion from the surrounding culture medium. Due to the highly impervious nature of the calcified bone matrix and fatty marrow it is relatively difficult to ensure adequate supply of soluble factors to the central regions of the explant. The reduced rate of mass transfer to the central parts of the explant also produces an extra complication when using standard viability techniques, with the central regions often remaining completely unstained. A number of viability assays are toxic and the longer incubation time required for maximal penetration can cause complications by killing the external layers of cells. Radioactive labelling of viable cells is routinely performed by the addition of $25 \mu \mathrm{Ci} / \mathrm{ml}{ }^{3} \mathrm{H}$-glycine into the culture medium for 24 hours (Figure 1). This method of viability assessment however does have some major drawbacks. ${ }^{3} \mathrm{H}$ is a weak $\beta$-emitter, resulting in long exposure times. Total assay time can be over five weeks, when including time for embedding the sample in resin and sectioning. The problems associated with the handling and disposal of radioactive isotopes, especially those such as ${ }^{3} \mathrm{H}$ which have a very long half life $\left(12.35\right.$ years in the case of $\left.{ }^{3} \mathrm{H}\right)$ has led to a general move towards non-radioactive methods.

Thiazolyl blue tetrazolium bromide (MTT) is a commonly used assay for cell viability. Early studies demonstrated that the yellow soluble tetrazolium salt is converted by metabolically active cells to an insoluble formazan, which can be dissolved and quantified spectrophotometrically (Mosmann, 1983). This method was further improved by removing the interference caused by phenol red and serum (Denizot and Lang, 1986). Although this assay was developed with cell proliferation in mind, the fact that the insoluble formazan crystals are retained within the cell also lends itself to histological studies. Under the correct conditions live stained cells can be identified within a section of tissue.

Live/ dead fluorescent labelling of cells using dyes such as cell tracker green (5-chloromethylfluoresceine diacetate - CMFDA) and ethidium homodimer 1 is a routine method carried out in many studies (Poole et al., 


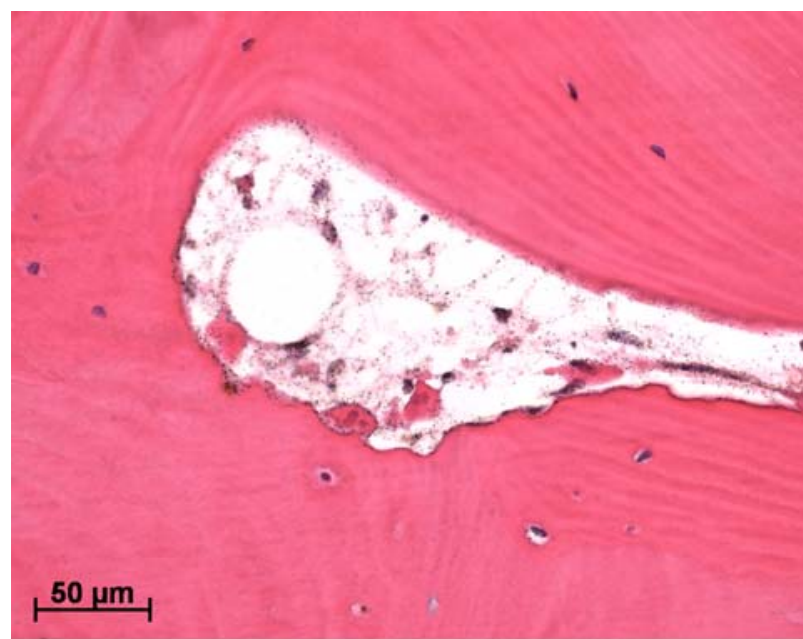

Figure 1: Whole human cancellous bone cores were incubated for $24 \mathrm{~h}$ at $37^{\circ} \mathrm{C}$ in $2 \mathrm{ml}$ medium containing $25 \mu \mathrm{Ci} / \mathrm{ml}^{3} \mathrm{H}$ - Glycine. The cores were then fixed, embedded in Technovit $9100 \mathrm{New}$ resin and $6 \mu \mathrm{m}$ sections cut. Slides were then exposed to emulsion and counterstained with haematoxylin and eosin. Pigmented areas indicating radioactive incorporation, and hence live cells, can be identified.

1996). Again, this assay has been optimised primarily for monolayer culture when a rapid assessment of viability is possible. The non-fluorescent CMFDA passes freely through cell membranes where the intracellular esterases cleave the acetate groups in metabolically active cells. The resultant molecule fluoresces at $517 \mathrm{~nm}$ and is impermeable to cell membranes, thus being retained within the cell where it produces a uniform cytoplasmic staining (Haugland, 2002). This retention is sustained and can therefore be used for long term cell tracking studies (Chen et al., 1997).

Lactate dehydrogenase is an enzyme found in most cells in the body and has been used previously to label live osteocytes and marrow cells (Wong et al., 1987). The assay involves the conversion of a soluble nitroblue tetrazolium indicator into an insoluble formazan salt which is retained within the cytoplasm of the cell. As it relies on enzymic activity, it is possible to freeze the samples and assay them at a later date, as long as the structural integrity of the cell is maintained. This is not possible with either the MTT or the CMFDA labelling of cells which require active mitochondria.

While working with bone samples the issue of decalcification plays a role in both processing time and how the sample must be sectioned. Decalcification softens the bone, making it easier to cut and allows for subsequent paraffin embedding and sectioning, but increases processing time and often causes a loss of marrow integrity. Sectioning techniques vary depending on the downstream application. Although cryosectioning has been used for undecalcified bone (Noble and Stevens, 2003), it is technically demanding due to the brittle nature of bone. It is therefore a method more suitable for immature bone which is less brittle.

Using cylindrical cancellous bone cores, $5 \mathrm{~mm}$ high and $9.5 \mathrm{~mm}$ in diameter, we aimed to compare various cell viability methods to determine which is the most suitable for assessing the viability of cultured cancellous bone cores. Ease of use, speed and ease of interpretation were all considered.

\section{Materials and Methods}

\section{Preparation of bone cores}

Cancellous bone explants were obtained either from ovine distal femora (3-6 years of age), bovine distal metacarpals (4 months of age) as waste material from the slaughterhouse or human femoral heads (obtained from a 70 year old female, an 80 year old female and one 71 year old male during total hip replacement) (Ethic Commission Graubünden approval 18/02). The skin, muscle, and tissue were removed from the ovine and bovine bone under sterile conditions, in a laminar flow hood. The bone tissue was cut into $5 \mathrm{~mm}$ thick sections with an Exakt 300 (Exakt Apparatebau GmbH \& Co. KG, DE) band saw. Cores, 9.5 $\mathrm{mm}$ in diameter, were drilled from the sections with a Synthes drill bit (Ref: 387.661, Synthes, Bettlach, Switzerland). Throughout all cutting procedures, the bone was irrigated with sterile $0.9 \% \mathrm{NaCl}$ at $4{ }^{\circ} \mathrm{C}$ (Fresenius Kabi NI2516. The cores were washed $2 \times 10$ minutes in $10 \mathrm{ml}$ of Hank's Balanced Salt Solution (HBSS) at $4^{\circ} \mathrm{C}$. A final wash of $10 \mathrm{ml} \mathrm{HBSS}$ containing 100,000 IU Penicillin/Streptomycin and $150 \mathrm{mg}$ Gentamicin per L for $30 \mathrm{~min}$ was then performed.

\section{Assessment of Viability}

Freshly prepared bone cores were used to compare the methods as it is expected that the whole core should be viable. Negative controls were bone cores incubated at $56^{\circ} \mathrm{C}$ for $18 \mathrm{~h}$ in DMEM $+10 \% \mathrm{FCS}$. The cores were then transferred to fresh medium and cultured at $37^{\circ} \mathrm{C}$ for three days. This was to allow a period of recovery to ensure that the loss of signal was not purely due to heat denaturation of the enzyme and therefore the cells were dead.

In one LDH experiment cores were cultured statically at $37^{\circ} \mathrm{C}$ with $5 \% \mathrm{CO}_{2}$ for 7 days in $50 \mathrm{ml}$ tubes containing $10 \mathrm{ml}$ of DMEM, $10 \%$ FCS, $5 \mathrm{mM} \beta$-glycerophosphate disodiumhydrate, $10 \mu \mathrm{g} / \mathrm{ml} \mathrm{L-ascorbic} \mathrm{acid-2-phosphate}$ and $50 \mathrm{IU} / \mathrm{ml}$ penicillin streptomycin. Medium was changed every two days.

\section{MTT Staining}

Thiazolyl blue tetrazolium bromide (MTT) (Sigma, M2128) was dissolved to a concentration of $10 \mathrm{mg} / \mathrm{ml}$ in DMEM $+10 \%$ FCS. Whole bone cores were incubated with $10 \mathrm{ml}$ of MTT solution at $37^{\circ} \mathrm{C}$ for $6 \mathrm{~h}$ or at $4^{\circ} \mathrm{C}$ for $3 \mathrm{~h}$ followed by $37^{\circ} \mathrm{C}$ for $3 \mathrm{~h}$. Alternatively, bone explants were sectioned to $250 \mu \mathrm{m}$ using a Leica annular saw (Leica AG, Glattbrugg, $\mathrm{CH})$. Throughout all cutting procedures, the bone was irrigated with sterile $0.9 \% \mathrm{NaCl}$ at $4{ }^{\circ} \mathrm{C}$ (Fresenius Kabi NI2516). The sections were kept moist in a 24 well plate containing DMEM $+10 \%$ FCS until all sections were prepared. Individual sections were incubated with $500 \mu \mathrm{l}$ MTT solution in a 24 well plate at $37^{\circ} \mathrm{C}$ for $4 \mathrm{~h}$ in a humidified environment. All incubations were carried out in the dark. 


\section{Fluorescent Staining}

Live/ dead staining was carried out using a combination of cell tracker green (live) and ethidium homodimer 1 (dead). This combination was determined in previous studies which demonstrated that both dyes survived resin embedding (data not shown). Fluorescent staining solution was $12 \mu \mathrm{g} / \mathrm{ml}$ cell tracker green (Molecular Probes) and 1 $\mu \mathrm{g} / \mathrm{ml}$ ethidium homodimer 1 (Molecular Probes) in DMEM.

Whole bone cores were incubated with $10 \mathrm{ml}$ fluorescent staining solution at $37^{\circ} \mathrm{C}$ for $6 \mathrm{~h}$ or at $4^{\circ} \mathrm{C}$ for $3 \mathrm{~h}$ followed by $37^{\circ} \mathrm{C}$ for $3 \mathrm{~h}$. The cores were then processed, embedded and sectioned as described below. Eight images (each image corresponding to $1.5 \mathrm{~mm}^{2}$ ) were taken from each section ( 2 sections per core, 3 cores per group) and from each image the penetration of stain was measured in three places. All analysis was performed blind, with coded samples.

Alternatively bone explants were sectioned to $250 \mu \mathrm{m}$ using a Leica annular saw (Leica AG, Glattbrugg, $\mathrm{CH}$ ). Throughout all cutting procedures, the bone was irrigated with sterile $0.9 \% \mathrm{NaCl}$ at $4^{\circ} \mathrm{C}$ (Fresenius Kabi NI2516). The sections were kept moist in a 24 well plate containing DMEM $+10 \%$ FCS until all sections were prepared. Individual sections were incubated with $500 \mu$ fluorescent staining solution in a 24 well plate at $37^{\circ} \mathrm{C}$ for $4 \mathrm{~h}$ in a humidified environment. All incubations were carried out in the dark.

After incubation, the cores were washed in sterile PBS. The cores were imaged on the Zeiss photomicroscope (Axioplan Imaging) and processed with Axiocam and Axiovision.

\section{Lactate Dehydrogenase (LDH) Staining}

Bone explants were sectioned to $250 \mu \mathrm{m}$ using a Leica annular saw (Leica AG, Glattbrugg, CH). Throughout all cutting procedures, the bone was irrigated with sterile $0.9 \%$ $\mathrm{NaCl}$ at $4{ }^{\circ} \mathrm{C}$ (Fresenius Kabi NI2516). The sections were kept moist in a 24 well plate containing DMEM $+10 \%$ FCS until all sections were prepared. The method used is a modification of earlier studies by Wong, Farquharson and Noble (Wong et al., 1982; Wong et al., 1987; Farquharson et al., 1992; Noble and Stevens, 2003). A base solution containing either 40\% polypep (Sigma) and $2 \mathrm{mM}$ Gly- Gly (Sigma G3915), pH 8.0 or 5\% Polypep (Sigma, P5115), 2 mM Gly- Gly and $0.75 \% \mathrm{NaCl}, \mathrm{pH} 8.0$ was prepared and stored at $4{ }^{\circ} \mathrm{C}$. The $\mathrm{LDH}$ solution was prepared freshly on the day of the assay by adding $60 \mathrm{mM}$ lactic acid (Fluka, 69771), $17.5 \mathrm{mg} \beta$-nicotinamide adenine dinucleotide NAD (final conc. $1.75 \mathrm{mg} / \mathrm{ml}$, Fluka 43410) to $10 \mathrm{ml}$ polypep base solution. The $\mathrm{pH}$ was adjusted to 8.0 with $5 \mathrm{M} \mathrm{NaOH}$ and $30 \mathrm{mg}$ Nitroblue Tetrazolium (NBT, Sigma, N5514) was added immediately prior to use. The medium was aspirated from the sections and the sections incubated in $500 \mu \mathrm{l}$ reaction medium for $4 \mathrm{~h}$ at $37^{\circ} \mathrm{C}$. The 24 well plate was sealed with parafilm to produce a humidified chamber. All incubations were carried out in the dark. When staining concurrently for live and dead cells, sections were preincubated with DMEM containing $1 \mu \mathrm{g} / \mathrm{ml}$ ethidium homodimer 1 for 10 $\min$ at $37^{\circ} \mathrm{C}$ in the dark. The section was then washed once with PBS before being transferred to the LDH solution.

Sections were then washed with warm $\left(37^{\circ} \mathrm{C}\right) \mathrm{PBS}$ and fixed with $4 \%$ formalin buffered to $\mathrm{pH} 7.4$ at $4{ }^{\circ} \mathrm{C}$.

\section{Histological processing of whole bone explants}

\section{Decalcification and cryosectioning of bone cores}

Bone cores were washed with 1 x PBS and fixed for $48 \mathrm{~h}$ in $4 \%$ buffered formalin at $4^{\circ} \mathrm{C}$. The cores were then suspended in $12.5 \%$ EDTA, $1.25 \% \mathrm{NaOH}$ in $\mathrm{dH} 2 \mathrm{O}$ for 5 days with gentle stirring and then left for $24 \mathrm{~h}$ at $4{ }^{\circ} \mathrm{C}$ in $5 \%$ sucrose PBS. The samples were placed at room temperature in Jung Tissue Freezing medium 30 min before being sectioned to $12 \mu \mathrm{m}$ sections and adhered to SuperFrost ${ }^{\circledR}$ Plus (Roth, Karlsruhe, D, no. H867) glass slides.

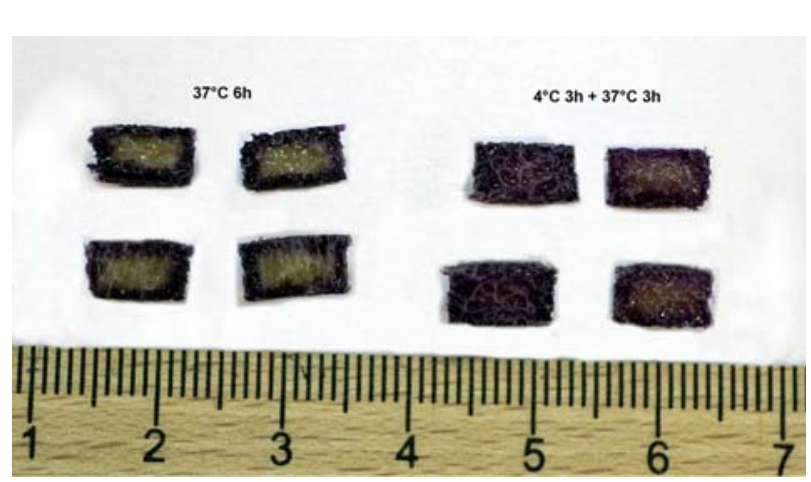

Figure 2: Whole ovine cancellous bone cores incubated at $37^{\circ} \mathrm{C}$ for $6 \mathrm{~h}$ demonstrated a ring of staining around the outside of the core (left), wrongly suggesting that the central areas are dead. Cores incubated for $3 \mathrm{~h}$ at $4^{\circ} \mathrm{C}$ followed by $3 \mathrm{~h}$ at $37^{\circ} \mathrm{C}$ show a more homogenous staining demonstrating live staining throughout the core (Right).

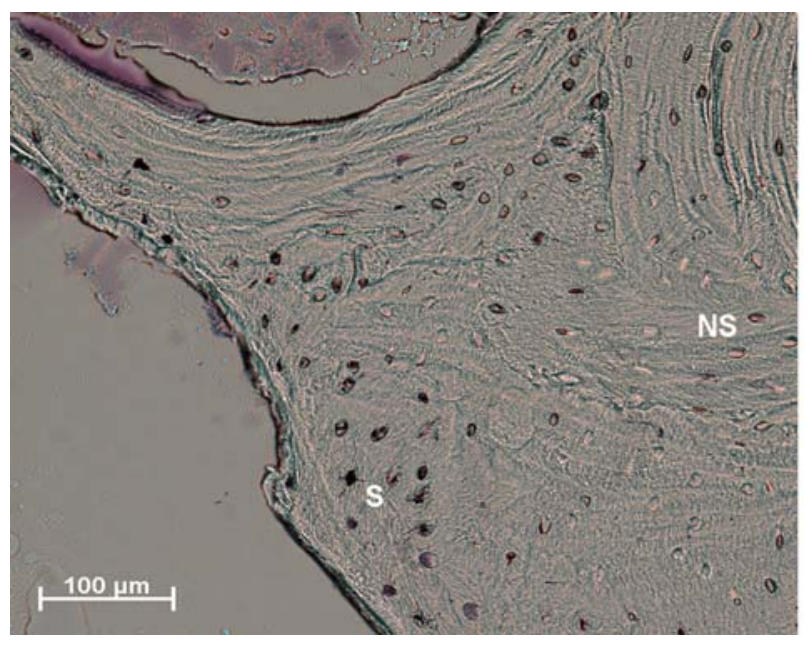

Figure 3: Whole ovine cancellous bone cores incubated at $37^{\circ} \mathrm{C}$ for $6 \mathrm{~h}$ were decalcified and cryosectioned. The ring of viable staining observed macroscopically (Figure 2) is maintained and stained cells (S) are clearly visible on the outer edge of the core. The cells further into the core do not stain under these conditions (NS). 


\section{Methylmethacrylate embedding and sectioning}

The cores were fixed with $70 \%$ ethanol for five days, at $4^{\circ} \mathrm{C}$, with two changes per day. The cores were then dehydrated in an ethanol series $(80 \%, 96 \%, 100 \%, 100 \%)$ with $24 \mathrm{~h}$ in each solution at $4{ }^{\circ} \mathrm{C}$. The ethanol was cleared from the samples by immersion in xylene (Siegfried, 235120-04) for 6-8h. Samples were embedded in Methylmethacrylate (MMA) according to manufacturers instructions (Fluka, 64200). Briefly, samples were embedded in solution 1 (pure MMA) for 3 days at $4^{\circ} \mathrm{C}$, then transferred to solution 2 (100 ml MMA containing $2 \mathrm{~g}$ dehydrated benzoyl peroxide catalyst) for 3 days at $4{ }^{\circ} \mathrm{C}$ and then finally in solution 3 (100 ml MMA containing 4g dehydrated benzoyl peroxide catalyst, dissolve on stirrer then add $25 \mathrm{ml}$ dibutyl phthalate) for 5 days at $4^{\circ} \mathrm{C}$ before being placed in a water bath at $20^{\circ} \mathrm{C}$ for polymerisation. The samples typically polymerised within 5-10 days.

Polymerised cores were cut with the Polycut E microtome (Reichert-Jung Leica, Glattbrugg, $\mathrm{CH}$ ) or HM355S rotary microtome (Microm International) with a D blade to give $6 \mu \mathrm{m}$ thick sections. Sections were adhered to SuperFrost ${ }^{\circledR}$ Plus (Roth, Karlsruhe, D, no. H867) glass slides with $80 \%$ ethanol and covered with polyethylene foil and paper before being clamped for $24 \mathrm{~h}$ at $50^{\circ} \mathrm{C}$.

\section{Mounting Thick sections}

Microscope slides were prepared by marking a square using clear nail polish. This produced a well in which the $250 \mu \mathrm{m}$ sections could be placed and covered with hydromount (National Diagnostics, Hull, England). A coverslip was then applied, taking care not to produce air bubbles, and the sections were viewed immediately. In some experiments mountant with DAPI was used (Vectorshield with DAPI, Vector Laboratories and Prolong Gold Antifade Reagent with DAPI, Molecular Probes, Leiden, Netherlands).

\section{Microscopy}

Slides were viewed on an Axioplan microscope. While viewing $250 \mu \mathrm{m}$ thick sections with visible light under 1.25 lens magnification, a $2 \mathrm{~mm}$ thick piece of white plastic was placed under the glass slide to diffuse the light and give better colour representation. For fluorescence microscopy, cell tracker green fluorescence and autofluorescence of the bone were visualised with Zeiss filter set \#10 (excitation BP450-490nm, beam splitter FT510nm, emission BP515-565nm) and ethidium homodimer 1 fluorescence was viewed with Zeiss filter set \#15 (excitation BP546nm, beam splitter FT580nm, emission BP590nm). Image analysis was performed using a Zeiss photomicroscope (Axioplan Imaging) and processed with Axiocam and Axiovision software.

\section{Results}

\section{MTT Viability staining}

Culturing freshly prepared whole bone cores in DMEM with MTT for $6 \mathrm{~h}$ at $37^{\circ} \mathrm{C}$ led to a ring of viable cells which stained around the outer circumference of the core. On

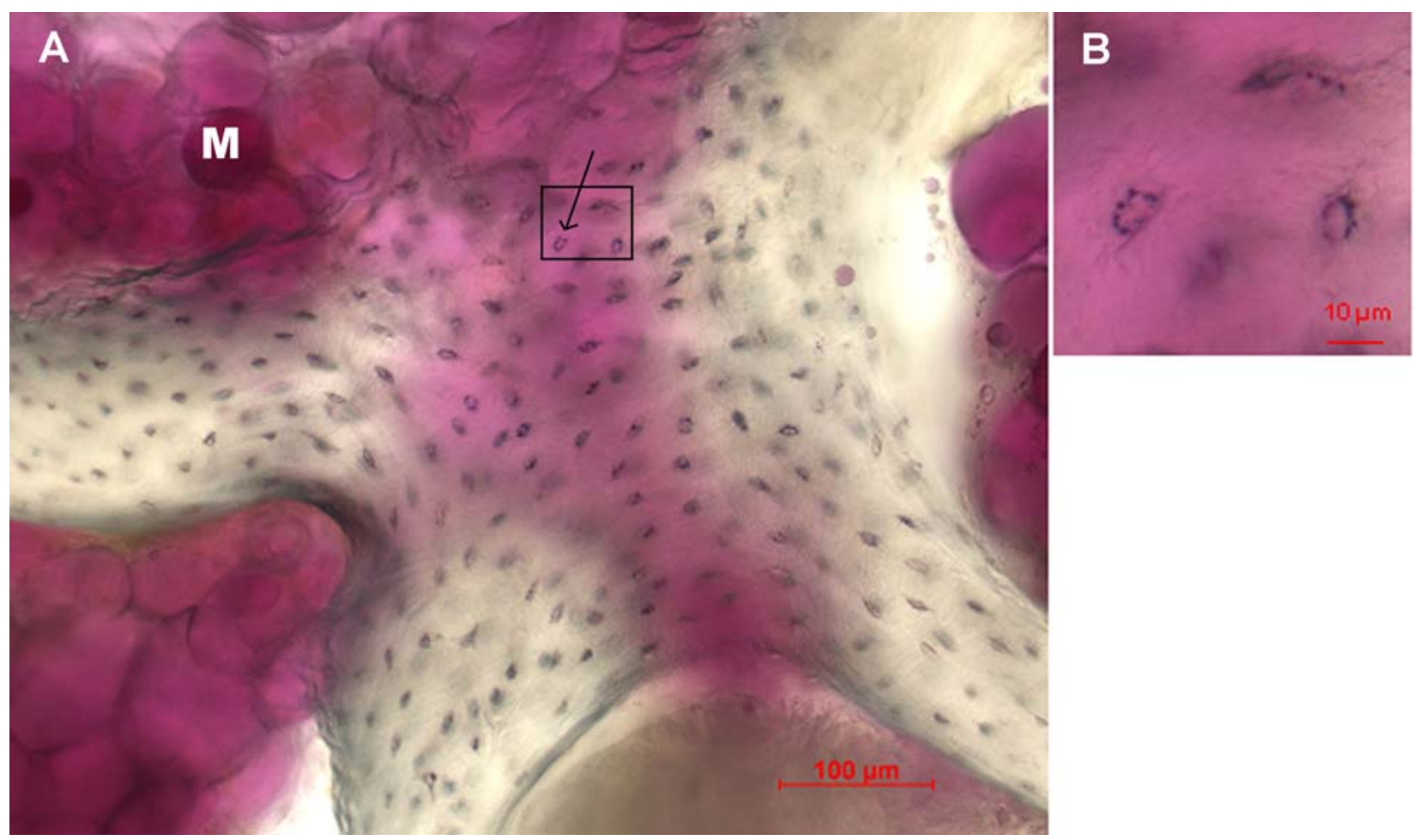

Figure 4: Sections ( $250 \mu \mathrm{m}$ thick) were cut from unfixed, undecalcified ovine cancellous bone cores and incubated with MTT for $4 \mathrm{~h}$. Punctate staining could be seen within the osteocytes, often appearing as a ring (arrowheadmagnified in B). The cells stained evenly throughout the sections, with central areas also staining as viable. Due to the thickness of the section, marrow integrity was well maintained and marrow cells produced a more diffuse type of staining (M). 

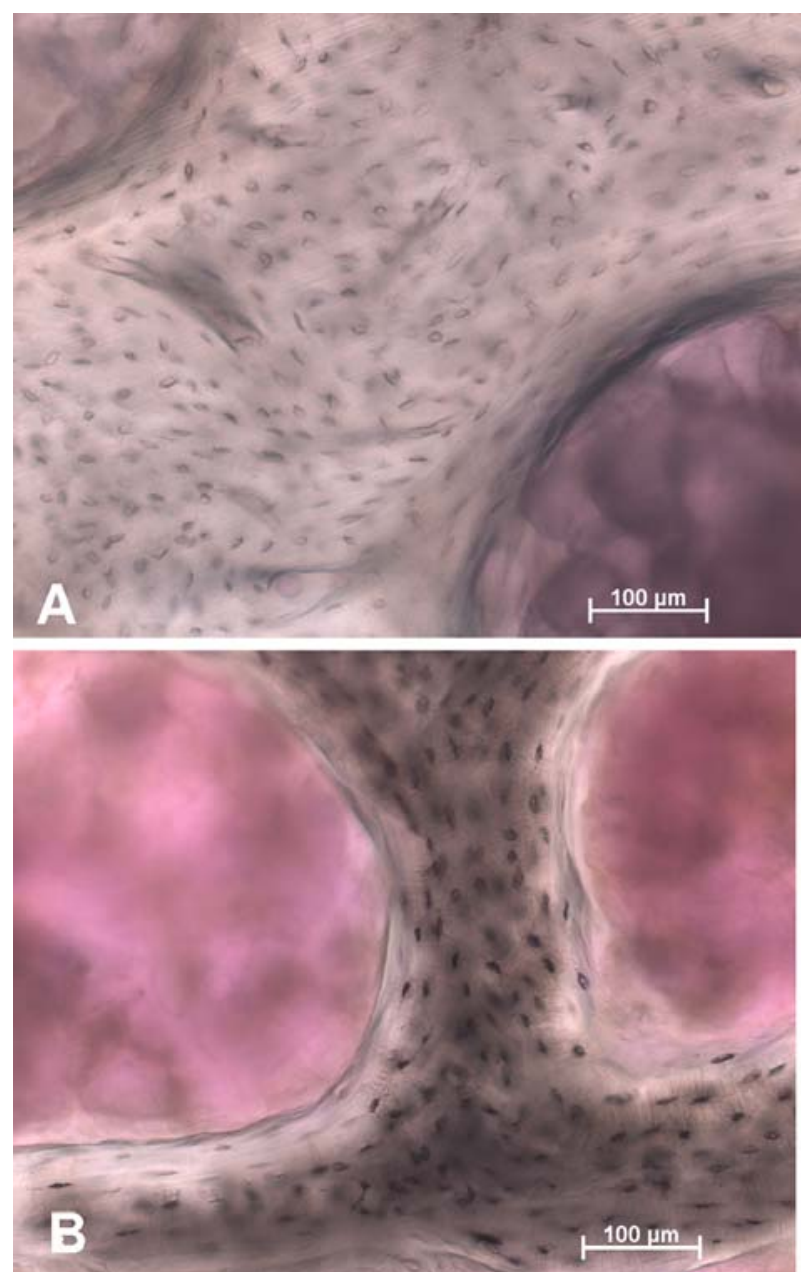

Figure 5: Ovine cancellous bone cores were heat killed at $56^{\circ} \mathrm{C}$ for $18 \mathrm{~h}$ then assayed for viable cells using MTT. When using a water based mountant all lacunae appear unstained as expected for dead tissue (A). When using water based mountant containing DAPI it was commonly observed that the cells appear darkly stained, falsely suggesting the cells are viable (B).
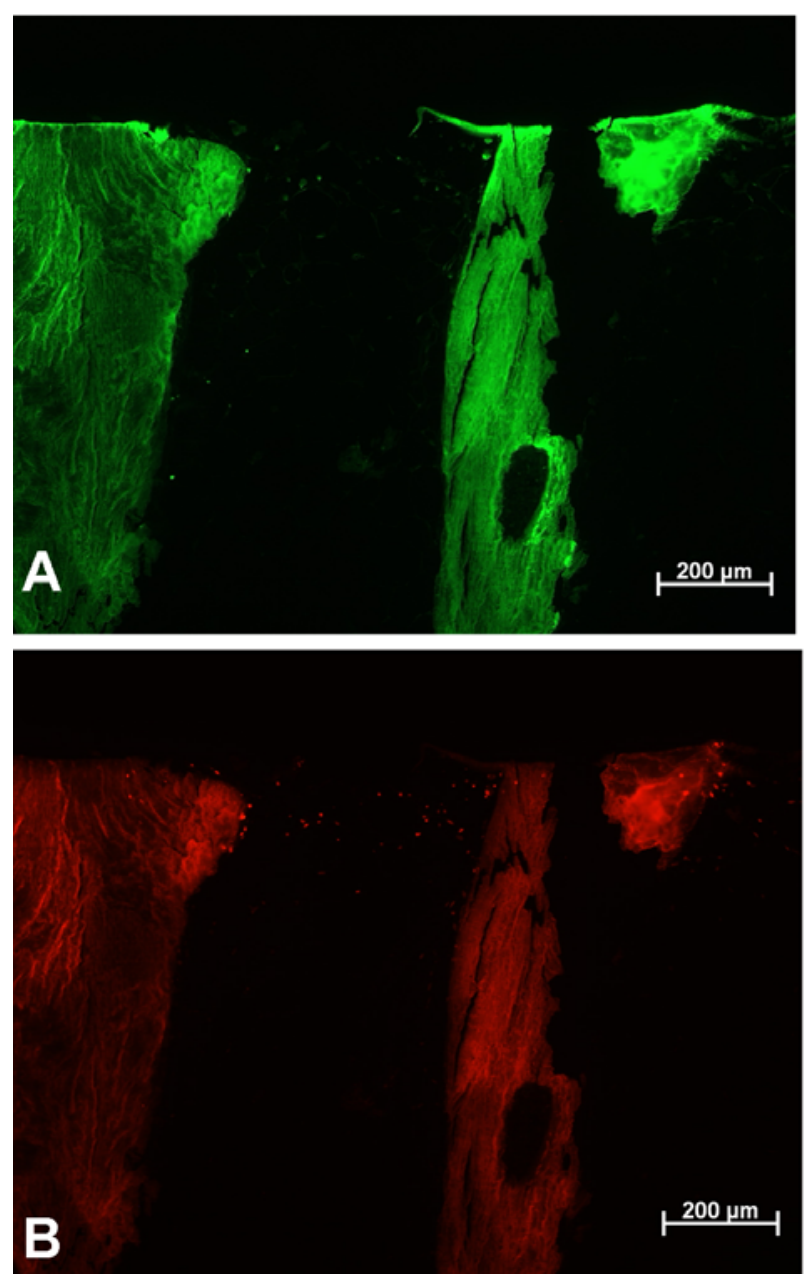

Figure 6: Whole human cancellous bone cores were stained for live (green) and dead (red) cells using fluorescent labels. After embedding $6 \mu \mathrm{m}$ sections were prepared and viewed using fluorescent microscopy. Stained marrow cells can be seen in both images but labelled osteocytes cannot be distinguished from the autofluorescence of the bone. Live cells were viewed using a 515-565nm emission filter (A) and dead using a 590nm emission filter (B). incubating the core for $3 \mathrm{~h}$ at $4^{\circ} \mathrm{C}$ followed by $3 \mathrm{~h}$ at $37^{\circ} \mathrm{C}$ the whole core then demonstrated viable staining (Figure 2). After decalcification and cryosectioning, the converted insoluble formazan is maintained within the viable osteocytes (Figure 3) but there is no maintenance of marrow structure. MTT staining of $250 \mu \mathrm{m}$ thick sections for $4 \mathrm{~h}$ at $37^{\circ} \mathrm{C}$ resulted in a good staining of all cells and led to good marrow preservation (Figure 4A). High magnification shows a ring of punctate staining within the osteocytes (Figure 4B). This would appear to be the mitochondria surrounding the nucleus and as the mitochondrion is the site of MTT conversion such a staining pattern is to be expected. The punctuate pattern made recognition of stained cells difficult to determine under lens magnifications lower than 20x. Viewing the sections using fluorescence microscopy (Zeiss Filter set $\# 10$ ), which led to autofluorescence of the bone, did not improve viability determination. The marrow cells however produced a more diffuse staining (Figure 4A). The choice of mountant was determined to be important when visualising MTT stained cells. It was observed that mountant containing DAPI could lead to the osteocyte lacunae appearing stained and would therefore be classed as viable (Figure 5). For this reason DAPI is to be avoided.

\section{Fluorescent staining}

Whole cores incubated with ethidium homodimer 1 and cell tracker green were embedded in MMA and $6 \mu \mathrm{m}$ sections were cut. Both stains survived the embedding process. Quantitative analysis of cores incubated with 1 $\mu \mathrm{g} / \mathrm{ml}$ of each dye indicated that both dyes penetrated to approximately the same depth $(400-550 \mu \mathrm{m})$ with cell tracker green penetrating further, although the difference was not significant. Contrary to the MTT assay, a preincubation at $4^{\circ} \mathrm{C}$ did not improve the penetration of the dyes. When viewing the section using fluorescent microscopy the autofluorescence of the bone led to a high background signal (Figure 6). This made interpretation of 

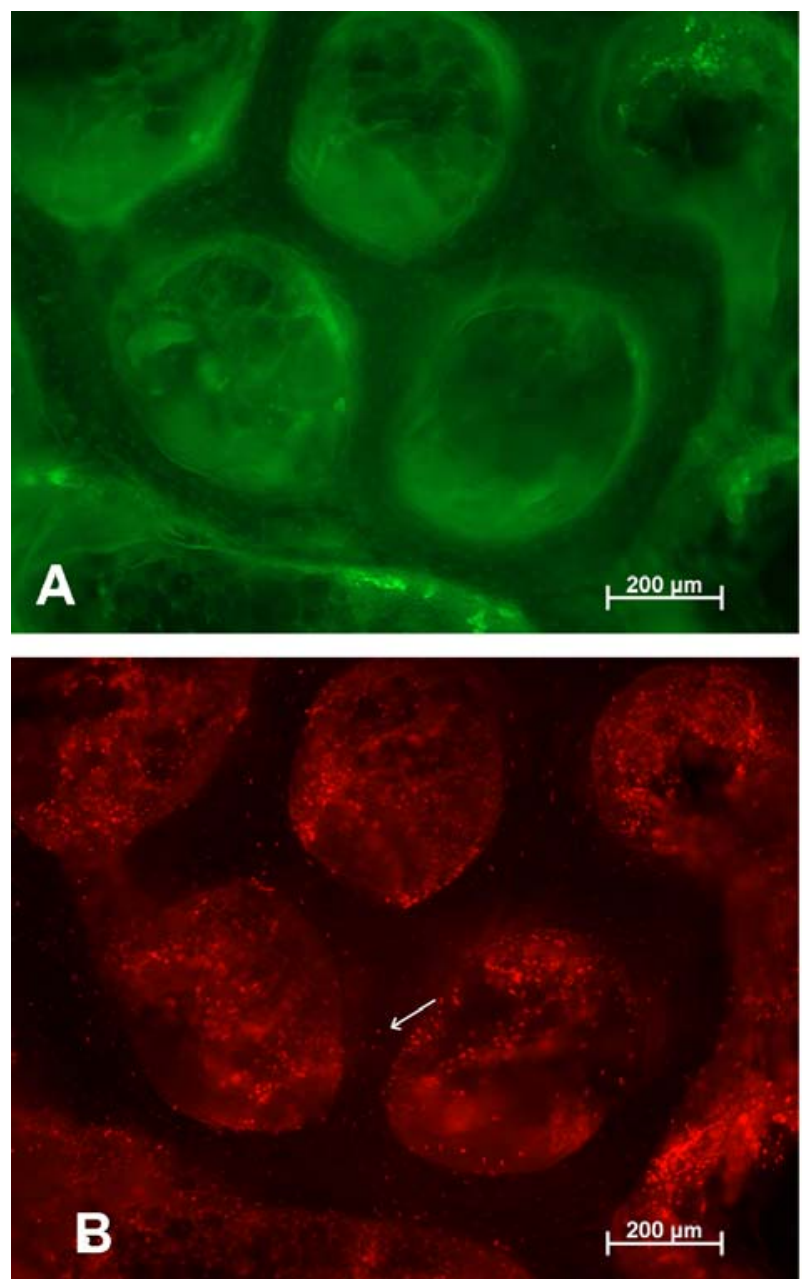

Figure 7: Sections $(250 \mu \mathrm{m}$ thick $)$ were cut from unfixed human cancellous bone cores and incubated with CMFDA (live) and ethidium homodimer 1 (dead) fluorescent dyes for $4 \mathrm{~h}$. The unfixed sections were then mounted with a water based mountant and viewed using fluorescent microscopy. When viewed using a 515-565nm emission filter (A) live cells were difficult to distinguish from the background fluorescence. Using a 590nm emission filter (B), dead cells could be seen more clearly including osteocytes within the bone (arrowhead).

the results difficult, especially for cell tracker green-stained cells. Under these conditions it was rare that any osteocytes were visualised with either dye.

Staining $250 \mu \mathrm{m}$ sections of freshly prepared bone for $4 \mathrm{~h}$ at $37^{\circ} \mathrm{C}$ produced an image with a high signal to noise ratio within the cancellous parts of the image. The autofluorescence of the bone made interpretation extremely difficult, especially with the cell tracker green-stained live cells (Figure 7a). The signal to noise ratio within the marrow was less but still made interpretation difficult. Osteocytes staining as dead could be seen within the bone (Figure 7b), although it was more difficult to determine whether the osteocytes staining was genuine or was a result of reflection within the osteocyte lacunae.

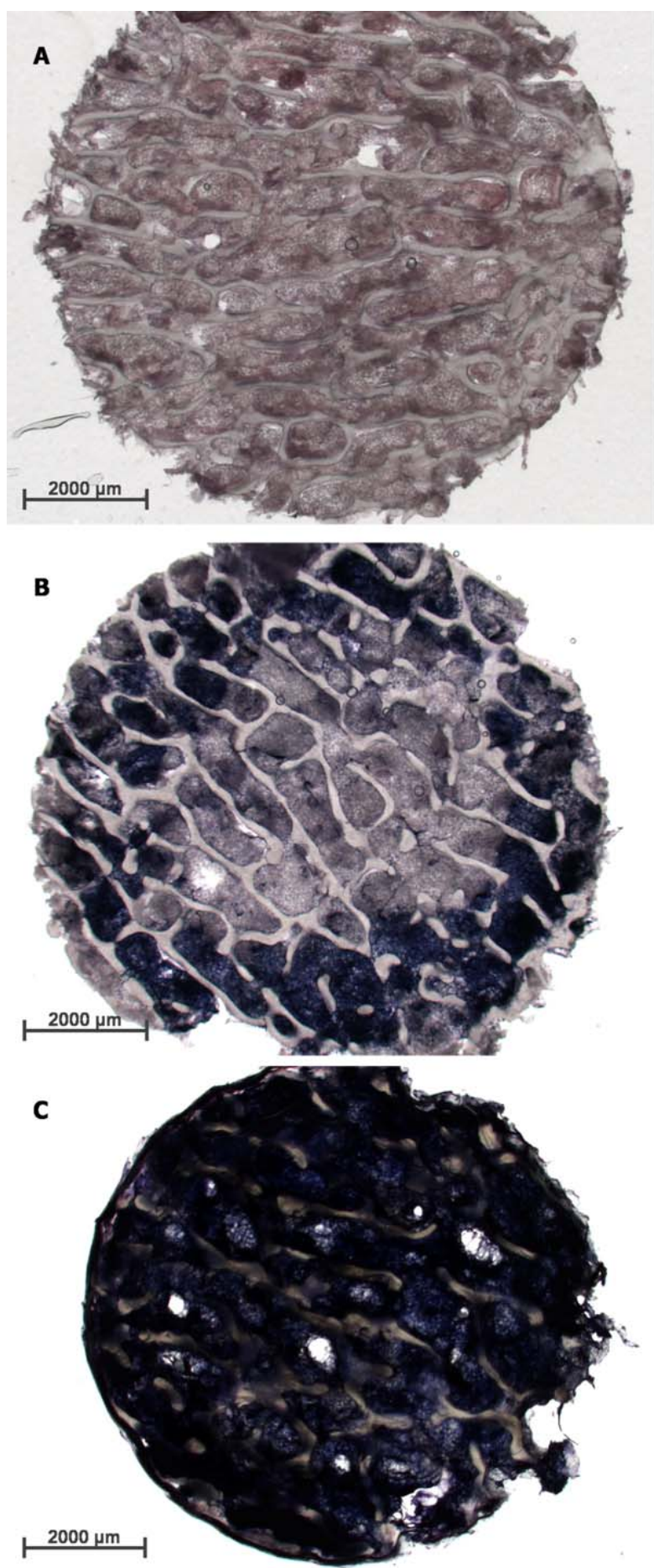

Figure 8: Overview image of sections from unfixed human cancellous bone cores stained for LDH activity. Heat killed $\left(56^{\circ} \mathrm{C}\right)$ bone $(\mathrm{A})$ demonstrates no staining and good marrow retention. After a period of static culture (B) cores show the expected staining pattern whereby the outer areas stain viable, with a dead central area. Freshly isolated live sections (C) show good viability throughout the core with good maintenance of marrow structure. 

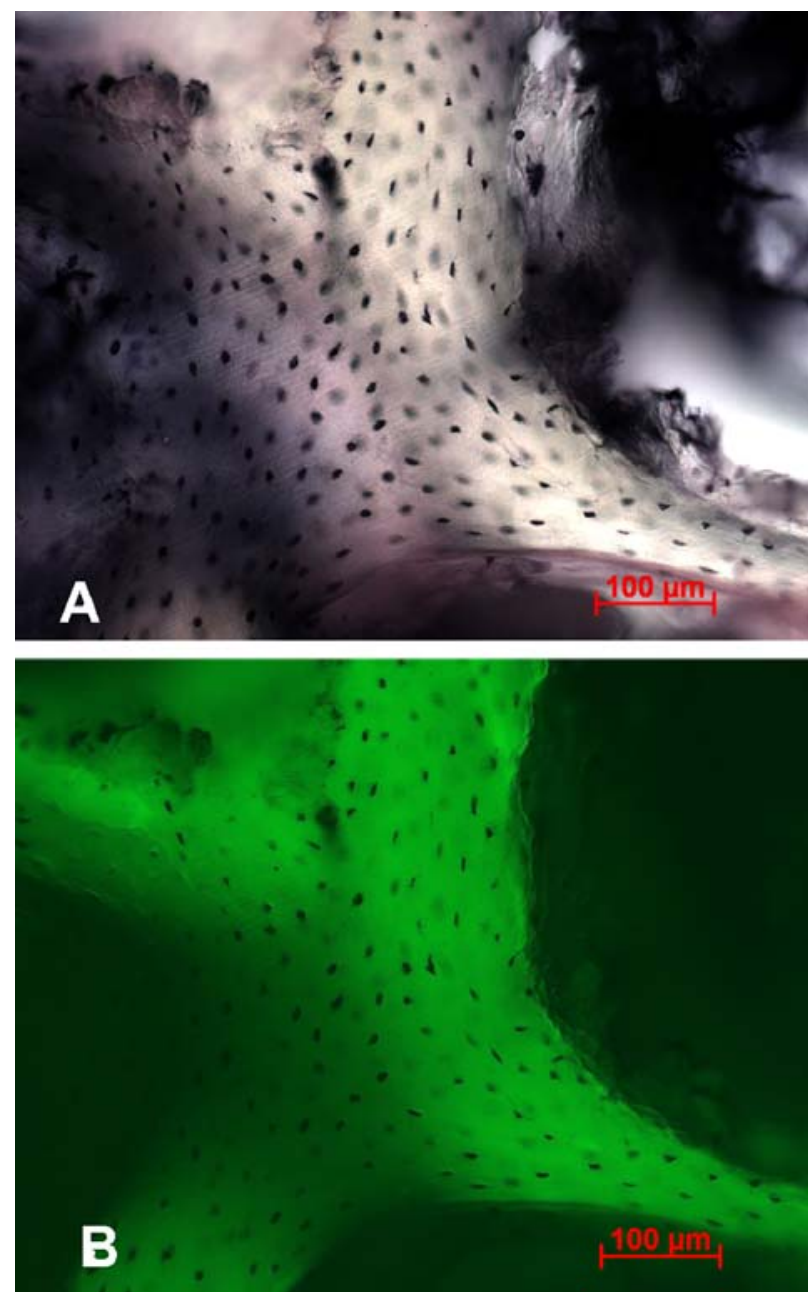

Figure 9: Sections of human cancellous bone (250 $\mu \mathrm{m}$ thick) were stained for LDH activity for $4 \mathrm{~h}$. Sections were mounted using a water based mountant and viewed immediately. The brightfield image shows the presence of numerous, darkly staining osteocytes (A). The corresponding image using the autofluorescence of the bone $(515-565 \mathrm{~nm}$ emission filter) enhances the contrast, leading to clearer definition of viable cells (B).

\section{Lactate Dehydrogenase}

Staining $250 \mu \mathrm{m}$ sections of bone for $4 \mathrm{~h}$ at $37^{\circ} \mathrm{C}$ led to good viability staining of both marrow and osteocytes throughout the section. Overview images clearly determine which areas of the marrow are alive, stained dark blue, and where the marrow is no longer viable (Figure 8). Due to the thickness of the sections good marrow structure was maintained. Under higher magnification it can be seen that the osteocytes stained evenly throughout the cell, as is to be expected when assaying for a cytoplasmic enzyme (Figure 9a). Viewing the same area using the bones natural autofluorescence (emission filter $515-565 \mathrm{~nm}$ ) provided the darkly stained osteocytes with greater contrast, allowing for easier viability determination (Figure 9b). Non-stained, hence non-viable, cells do not contain insoluble formazan crystals and as such are not visible under autofluorescence. When 40\% polypep base solution was used, penetration into the bone matrix was relatively poor and only the very upper surface of the mineralised bone stained. When using a 5\% polypep base solution the viscosity was greatly reduced, and therefore penetration into the mineralised bone was enhanced (Figure 10). When viewing through the section, multiple focal planes could be achieved before the limitations of the microscope prevented sharp images being produced. When taking multiple images from varying depths into the tissue it is interesting to note that no osteocyte was sharply in focus in more than one focal plane, which assists with quantification. A preincubation with ethidium homodimer 1 labelled dead nuclei, producing an image that could be combined with the brightfield image to estimate live versus dead cells (Figure 11).

\section{Discussion}

The comparison of the various techniques has demonstrated that great care needs to be taken when transferring assays normally performed in a two dimensional environment to a three dimensional structure, especially when diffusion is limited such as in bone. When assaying a whole cancellous bone core, approximately 10 $\mathrm{mm}$ diameter and $5 \mathrm{~mm}$ in height, each assay used led to artefacts when carried out at $37^{\circ} \mathrm{C}$. In the case of MTT this could be overcome by cooling the sample first and allowing the assay mix to penetrate as the cells are less metabolically active. This would be important to consider if using the method for $3 \mathrm{D}$ tissue engineering constructs or 3D biomaterials loaded with cells. While MTT may be useful for a macroscopic overview, it was seen that under high magnification identification of cells containing stained mitochondria was difficult and could only be performed successfully at very high magnifications. This reduces the numbers of cells that can be analysed within a reasonable timeframe and is likely to result in greater discrepancies when deciding which cell is viable. Both the MTT staining and the LDH staining label only viable cells and therefore cannot be used to compare dead versus live cells. For this reason we performed the viability assays on freshly isolated samples to set as a baseline control. The groups were then compared to each other and the time zero control.

Fluorescent labelling of cells caused many difficulties, due to the autofluorescence of the bone, which in most cases masked any green fluorescing osteocytes. The source of autofluorescence in bone is unclear. It is known to increase with age and decalcification does not quench the autofluorescence (Prentice, 1967). Due to the complications arising from the autofluorescence we believe fluorescent labelling of cells is not to be recommended, especially for green fluorochromes or studies involving osteocytes.

We found that the LDH assay on thick fresh sections was an easy and quick method for identifying viable cells. A broad overview of viability can be established by viewing stained marrow under low magnification, while a more detailed, high magnification analysis of individual cells such as osteocytes is also possible. The LDH present within the cytoplasm is still active for approximately 36 hours after death (Wong et al., 1987). This offers the advantage that cells killed during the cutting of the sections 

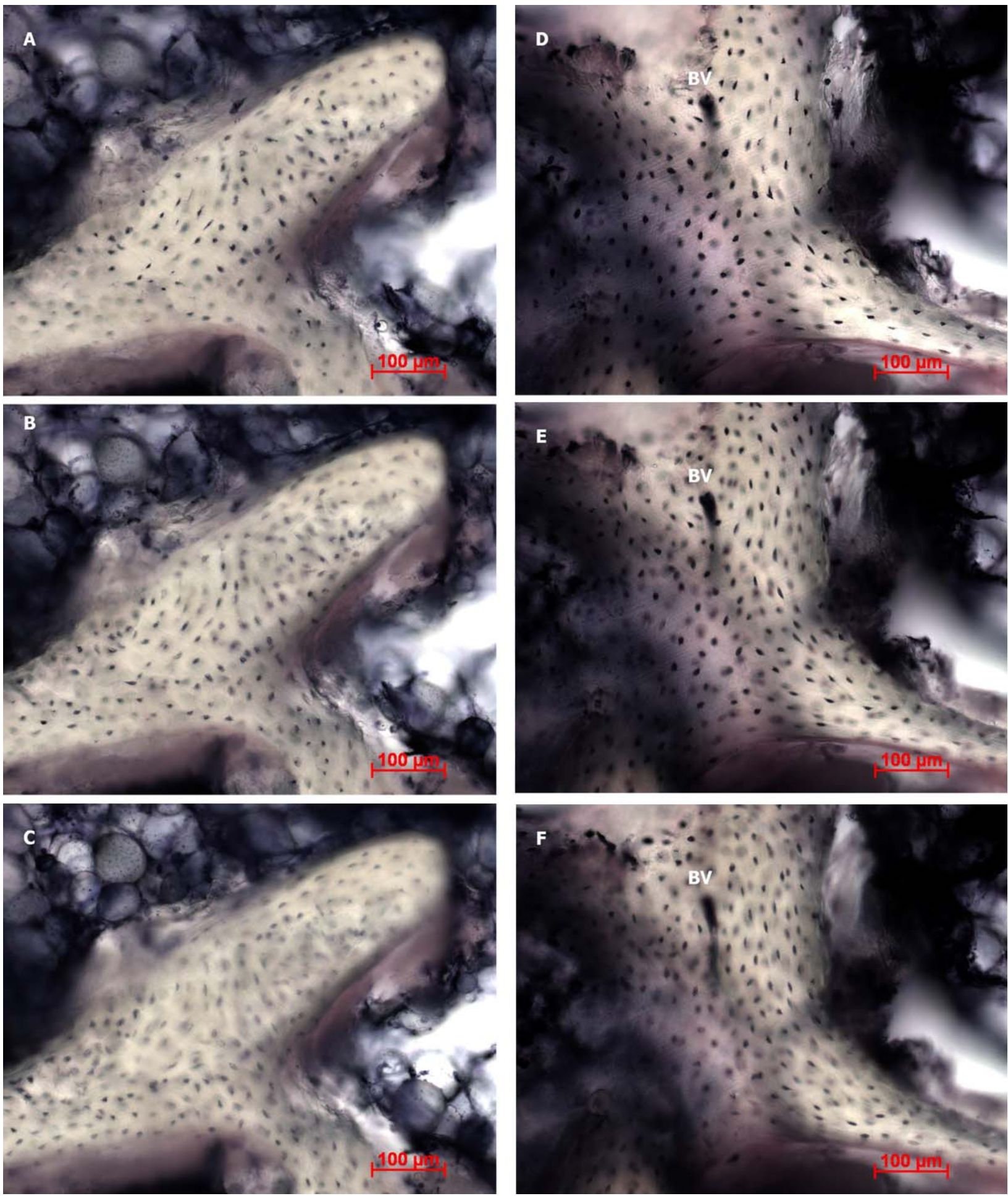

Figure 10: Sections of human cancellous bone ( $250 \mu \mathrm{m}$ thick) were stained for LDH activity for $4 \mathrm{~h}$. Sections were mounted using a water based mountant and viewed immediately. Viewing the section at different focal planes demonstrates that the 5\% polypep (right hand images) penetrates much deeper into the mineralised bone than $40 \%$ polypep (left hand images). The uppermost focal plane (A, D) demonstrates numerous stained osteocytes with distinct edges. Focussing deeper into the tissue $(\mathrm{B}, \mathrm{E})$ reveals a number of stained osteocytes at both concentrations, but more are visible with 5\%. At a deeper focal plane $(\mathrm{C}, \mathrm{F})$ very few sharply focussed stained osteocytes can bee seen with $40 \%$ (C) whereas 5\% still shows a substantial number of stained cells (F). A blood vessel (BV) can be seen passing through the mineralised bone. It is also noteworthy that no osteocytes are sharply in focus in more than one focal plane. This assists with a more accurate quantification. 


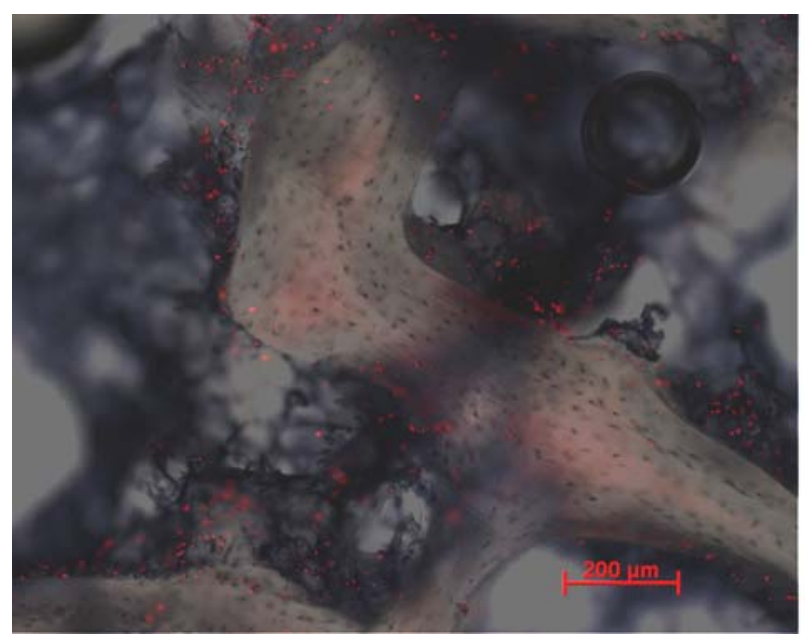

Figure 11: Sections of human cancellous bone (250 $\mu \mathrm{m}$ thick) were incubated with DMEM containing 1 $\mu \mathrm{g} / \mathrm{ml}$ of ethidium homodimer for $10 \mathrm{~min}$ at $37^{\circ} \mathrm{C}$. The section was then washed with PBS and stained for LDH activity for $4 \mathrm{~h}$. The section was mounted using a water based mountant and viewed immediately. The dead (red labelled) cells were visible as were darkly stained osteocytes.

will still show as live, therefore removing any cutting artefact. It should be taken into consideration however during short term studies, as weakly staining cells may have been dead for a few hours. We have found that treating the bone at $56^{\circ} \mathrm{C}$ for 18 hours is an effective method to kill the bone, and even if further cultured for 3 days to enable a period of recovery no cells stained for LDH. The use of polypep as a stabilising agent to maintain cellular structure has been previously described (Stuart et al., 1969; Noble and Stevens, 2003). The 40\% described (Noble and Stevens, 2003) is used on thin (8-12 $\mu \mathrm{m})$ sections in order to preserve the cellular structure to a greater extent. Such a high concentration is more suitable for thinner sections as we have noted there is little penetration into the mineralised bone of thicker sections. By reducing the polypep concentration to $5 \%$, while maintaining osmolality, we have seen that good structural integrity and penetration into the mineralised bone can be achieved. As the assay is carried out using a standard fluorescence microscope with minimal processing, large numbers of cells per section can be counted quickly. The use of autofluorescence, to identify viable osteocytes more clearly, lends itself to image analysis using a macro increasing the area that can be analysed while reducing the time required and eliminating operator bias. Higher quality human, ovine and bovine bones have all been assayed successfully using the LDH method. Previous work has also shown that the LDH assay can be performed on cut sections that were ground from $200 \mu \mathrm{m}$ to $50 \mu \mathrm{m}$ before assaying (Wong et al., 1982).

The LDH method in its current form is not suitable for the analysis of osteoporotic bone, as the sample will not produce thick cuts of sufficient quality while being sectioned fresh. In such situations the cryostat method may be more valuable, with the lower quality bone being more easily cut while undecalcified.

The use of thicker sections raises the question of ease of quantification, as quantification is more usually carried out on thin $(\sim 6 \mu \mathrm{m})$ sections. While using thin sections guarantees a fixed thickness, it can cause complications, especially with marrow cells, when the cells are much larger than the thickness of the cut. Limitations within microscopy provide a relatively constant depth of field which can be estimated mathematically. While quantifying osteocyte number, we have started to use the autofluorescence of the bone as the simplest way of visualising the cells. When using an emission filter of 515$565 \mathrm{~nm}$, a 20x optic with a numerical aperture (N.A) value of 0.5 the depth of field will approximate to $4.12-4.52 \mu \mathrm{m}$. When using an emission filter of 515-565 nm, a 10x optic with an N.A value of 0.3 the depth of field will approximate to $11.44-12.55 \mu \mathrm{m}$. As the diameter of an average human osteocyte is normally estimated to be approximately 10 $15 \mu \mathrm{m}$, the use of a $20 \mathrm{x}$ optic is therefore to be recommended. All of the above values are approximations; the exact set-up of the microscope will determine the final figures, most notably increasing the N.A. value of the lens will decrease the depth of field. It is interesting to note that when looking at images generated from successive focal planes it can be seen that no osteocyte was sharply in focus in more than one image (Figure 10). Thus, when counting only sharp edged cells, errors due to the thickness of the section can be reduced. Furthermore, any errors caused by the thickness of the section will occur in both treated and untreated samples, therefore the relative counts can still be compared.

The LDH assay described provides an excellent method for assessing viability in tissues which suffer from low rates of mass transfer. Although the assay is described for use on cancellous bone tissue, it is already being used within our institute for other tissues such as intervertebral disc. We believe it will also be a valuable tool to assess the spatial distribution of live cells within three dimensional tissue engineered constructs.

In conclusion, when deciding which viability assay to adopt for a particular study it is important to understand the limitations of each assay. The diffusion into the bone is a major issue and can be overcome by applying the assay to cut sections. As marrow cells can be as large as $80 \mu \mathrm{m}$ in diameter, sections thinner than this can pose problems retaining marrow cells and structure, especially as marrow has difficulty in adhering to glass slides. Whole cell stains, such as that for the cytoplasmically located LDH, enable an easier determination as to which cell is positive and which negative when compared with stains localised to a particular organelle, such as MTT in the mitochondrion. Modification of the LDH assay to incorporate the use of $5 \%$ polypep base solution led to an improved penetration with easily identifiable osteocytes and well stained, intact marrow cells on thick sections. 


\section{Acknowledgements}

The authors would like to thank Christoph Sprecher for his microscopy advice and Nora Goudsouzian for help with resin embedding and thin sectioning. This work has been funded by $3 \mathrm{R} \# 78 / 01$ and \#86/03, and ESA MAP project AO 99-122.

\section{References}

Chen AC, Nagrampa JP, Schinagl RM, Lottman LM, Sah RL (1997) Chondrocyte transplantation to articular cartilage explants in vitro. J Orthop Res 15: 791-802.

Denizot F, Lang R (1986) Rapid colorimetric assay for cell growth and survival. Modifications to the tetrazolium dye procedure giving improved sensitivity and reliability. J Immunol Methods 89: 271-277.

Farquharson C, Whitehead C, Rennie S, Thorp B, Loveridge N (1992) Cell proliferation and enzyme activities associated with the development of avian tibial dyschondroplasia: an in situ biochemical study. Bone 13: 59-67.

Haugland R (2002) Handbook of fluorescent probes and research products. Molecular Probes, Ninth Edition (http://probes.invitrogen.com/handbook/).

Mosmann T (1983) Rapid colorimetric assay for cellular growth and survival: application to proliferation and cytotoxicity assays. J Immunol Methods 65: 55-63.

Noble BS, Stevens HY (2003) Techniques for the study of apoptosis in bone. Methods Mol Med 80: 225-236.

Poole CA, Brookes NH, Gilbert RT, Beaumont BW, Crowther A, Scott L, Merrilees MJ (1996) Detection of viable and non-viable cells in connective tissue explants using the fixable fluoroprobes 5-chloromethylfluorescein diacetate and ethidium homodimer-1. Connect Tissue Res 33: 233-241.

Prentice AI (1967) Autofluorescence of bone tissues. J Clin Pathol 20: 717-719.

Stuart J, Bitensky L, Chayen J (1969) Quantitative enzyme cytochemistry of leukaemic cells. J Clin Pathol 22: 563-566.

Wong SY, Dunstan CR, Evans RA, Hills E (1982) The determination of bone viability: a histochemical method for identification of lactate dehydrogenase activity in osteocytes in fresh calcified and decalcified sections of human bone. Pathology 14: 439-442.

Wong SY, Evans RA, Needs C, Dunstan CR, Hills E, Garvan J (1987) The pathogenesis of osteoarthritis of the hip. Evidence for primary osteocyte death. Clin Orthop Relat Res 214:305-312.

\section{Discussion with reviewers}

Christine Halleux: Using the LDH assay, did you test the effect of cooling down the samples (cfr MTT assay) on the cell viability itself?
Authors: So far that is not a study we have done, although it would also be interesting from the point of view of cold storage of bone prior to use in applications such as cancellous bone grafting.

Christine Halleux: Could you expand on your experience with analysing osteoporotic bone?

Authors: We receive numerous samples of human bone from the replacement of osteoarthritic femoral heads. A proportion of these are also osteooporotic and the weak structure of the bone makes cutting the fresh, unfixed bone difficult. In these samples we have tried cutting thicker sections, which in some cases allows sections to be cut. In very poor quality bone the sample is prone to disintegrate on cutting. We are currently trying to develop methods to get around this problem. We have tried cryosectioning this material but find marrow loss to be an issue and also the maintaining the cancellous bone structure is quite difficult.

Anita Ignatius: Have you already applied the described techniques to cell seeded scaffolds and if yes what are your experiences?

Authors: So far we have focussed our work on cancellous bone. This was where the complications for our work lay. We have discussed the methods with other groups who are working with cell seeded scaffolds and they are trying the LDH method on their scaffolds, particularly where they have the problem that the scaffold autofluoresces.

Anita Ignatius: Have you also investigated larger bone cores and which size is the limit for cultivation and penetration of reagents? Have you investigated cortical bone?

Authors: We have worked entirely with cancellous bone and cores of $9.5 \mathrm{~mm}$ by $5 \mathrm{~mm}$ deep. When investigating the penetration of dyes into these whole cores we frequently observed problems obtaining penetration further than about $1 \mathrm{~mm}$.

Anita Ignatius: Is there any reliable staining technique for embedded bone section to detect viable cells?

Authors: Most viability techniques rely on a metabolic conversion of a dye reagent or the incorporation of radioactivity into protein produced by live cells. This therefore requires that the reagents are applied on fresh tissue before embedding. As long as the dye survives the embedding process it can be used on embedded bone. The choice of embedding will also play a role, whether it is undecalcified, resin embedded or decalcified paraffin embedded will determine which dyes survive the embedding process and what post embedding methods could be applied. If the bone has already been embedded and sectioned it is possible to look at cell morphology to give an indication of whether the cell was viable at the time of embedding, but this is technically demanding, is time intensive and cannot be considered to be conclusive. 